\title{
Electrolytic polishing of compacted graphite iron for revealing subsurface graphite of honed cylinders
}

\author{
João Luiz do Vale ${ }^{1}$, Victor de Cerjat Beltrão ${ }^{2}$ \\ Giuseppe Pintaúde ${ }^{2}$
}

\author{
${ }^{1}$ Universidade Tecnológica Federal do Paraná, UTFPR, Campus Londrina. Av. dos Pioneiros, 3131, CEP: 86036370, \\ Londrina, Paraná, Brasil. \\ ${ }^{2}$ Universidade Tecnológica Federal do Paraná, UTFPR , Curitiba, Paraná, Brasil. \\ e-mail: joaovale@utfpr.edu.br,victorbeltrao@me.com, pintaude@utfpr.edu.br
}

\begin{abstract}
The superficial characteristics of honed surfaces are relevant for the tribological performance of cylinders of internal combustion engines (MCI). Recent studies found a correlation between the occurrence of the phenomenon called folded metal and the presence of graphite of cast irons. However, the honing process tends to overlap the graphite, such that an application of a technique to remove a thin layer of material, exposing the graphite, would be useful. This paper aims to determine the best condition, of electric potential and time, for the exposition of graphite in honed surfaces using a technique of electrolyte polishing. The polishing was made on the concave surface with aid of a polishing mask developed for this matter. Samples of honed cylinders were removed from MCI manufactured using a compacted graphite iron. The characterizations were done through metallography and white light interferometry. To determine the ideal condition, several conditions of polishing were tested. For the verification of the repeatability, five repetitions were performed with the best condition. The results showed satisfactory repeatability, with an exposition of graphite and the matrix etching. The roughness of the polished region presented considerable uniformity, with a significant change of roughness in comparison to the honed surface. Furthermore, removal of the characteristic topography of the honed surface was observed. The layer removed showed little variation in depth along the polished region, with values close to $5 \mu \mathrm{m}$. This value accomplishes the demand of layer removal for the exposition of subsurface graphite.
\end{abstract}

Keywords: Electrolyte polishing; Compacted graphite iron; Honing.

\section{INTRODUCTION}

According to SABEUR et al. [1], in serial manufacturing, the finishing of cylinders of internal combustion engines is usually obtained by honing. CORRAL and CALVET [2] showed that the topographic characteristics of these surfaces are very relevant to the tribological performance of engine system, and they are composed of valleys and plateaus. The plateaus are, generally, related to friction and wear phenomena, because these areas are in direct contact with the piston rings. On the other hand, MEZGHANI et al. [3] show that the valleys are associated with the lubrication and they serve as reservoirs, generating a network of channels where the oil may flow through [2].

An inherent phenomenon to the honing process is the folded metal [4]. These portions of material tend to obstruct the grooves, and further may be detached during the operation of the engine. Hence, there is a tendency of scratch in the axial direction of the cylinder, which allows the passage of fluids to the combustion chamber, as demonstrated by DIMKOVSKI et al. [5].

VALE et al. [6] showed that the presence of graphite affects the occurrence of the folded metal in the honed process. In most of the cases, the subsurface location of graphite is relevant to the plastic deformation of cast irons matrix, leading to the folded metal occurrence. However, it is verified that graphite is often covered by the honing process. Thus, the removal of a layer as thin as possible is required to correlate the folded metal phenomenon with the graphite immediately below the surface. In this way, to develop a suitable technique to reveal the graphite in honed surfaces is useful.

The use of etching techniques for removal specific micro-constituents in the cast irons is well reported by the literature. For example, RIVERA et al. [7] made use of a color etching to create color patterns to iden- 
tify the microsegregation in ductile irons. For white cast iron, their carbides can be better identified using a selective etching to remove deeply the matrix, as used by SINATORA et al. [8] for identifying $\mathrm{M}_{3} \mathrm{C}$ and $\mathrm{M}_{7} \mathrm{C}_{3}$ carbides, and by DA SILVA and BOCCALINI JR. [9] for MC and $\mathrm{M}_{2} \mathrm{C}$ ones. Finally, it is worthwhile to cite the investigation conducted by WOLLMANN et al. [10], who used an etching for removal successive layers of ductile iron for measuring residual stresses.

Within this context, this paper aims to identify the best condition for electrolytic polishing in concave surfaces of honed cylinders of cast iron to expose the subsurface graphite. Besides this, an evaluation of the repeatability of the technique is presented.

\section{MATERIAL AND METHODS}

The specimens were extracted from cylinders of internal combustion engine blocks, model Ford Griffin V8. The blocks, provided by Tupy S.A., were manufactured in compacted graphite iron. The class of this material is the GJV450 (ISO 16112). After casting, the cylinders were honed. The applied honing process was the plateau type. For this process, diamond tips - D151 and D15 were used for roughing and finishing, respectively. The feed rate and rotation speed were $12.4 \mathrm{~m} / \mathrm{min}$ and $130 \mathrm{rpm}$, respectively.

The apparatus used for polishing was the ElectroMet ${ }^{\circledR} 4-$ Buehler device. In general, the polishing procedure is made by positioning the sample above a mask. It should create a conformal-contact with the surface, allowing to carry the solution to the region to be polished. The electrical contact is created using a rod, which serves to apply a force to keep the sample fixed. An acid solution was used, presenting the following constitution on a volumetric basis of 1 liter:

- $700 \mathrm{ml}$ of Ethanol (95\% Vol.);

- $100 \mathrm{ml}$ of 2-Butoxi-Ethanol;

- $200 \mathrm{~mL}$ of Perchloric acid (30\% Vol.).

To perform the polishing a customized mask was manufactured using polyamide 6 , suitable to establish the contact with the concave surface of the cylinder. Figure 1 shows details of the mask and the mounting with the specimen. In this way, the polishing area kept itself restricted to the slot of $6 \mathrm{~mm} \times 20 \mathrm{~mm}$ in the central section of the mask. The surfaces were cleaned with isopropyl alcohol before each procedure.

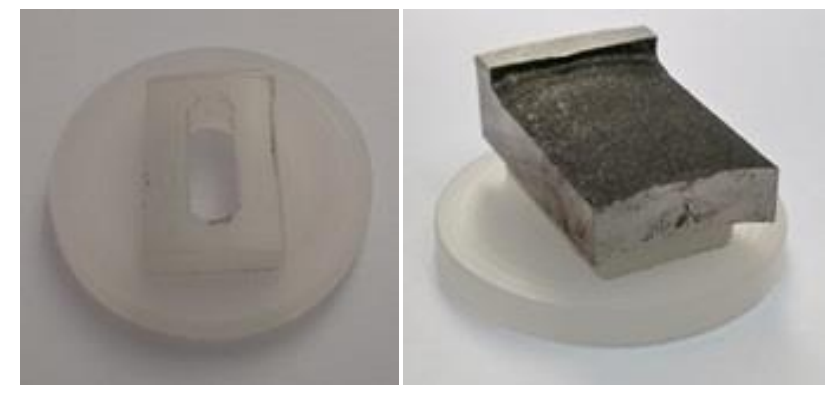

(a)

(b)

Figure 1: Details of the mask for electrolytic polishing. (a) Mask. (b) Mounting with the specimen.

The possible settings in the apparatus are electric potential, time, and solution flow. The limits indicated in the data sheet's apparatus were taken into account for determining the electric potential and time range for the electrolytic polishing. Thereby, the selected ranges were 20 to $40 \mathrm{~V}$ and 30 to $90 \mathrm{~s}$. To avoid a factorial design, the test conditions were evaluated using a qualitative chart based on the images of etched surfaces, aiming to identify the best condition of polishing. This approach will become clear in the results and discussions section. Two runs of tests were necessary, with 5 conditions for each, as shown in Table 1. In these steps, a qualitative evaluation was made using images obtained with an optical microscope.

It is worth pointing out that during the apparatus set up, a lower fluctuation of electrical current during the polishing was observed, due to two conditions. Firstly, the grinding of an area in contact with the electrode apparatus; and secondly, the adjustment of solution flow for higher levels.

After the determination of the ideal polishing condition, 5 repetitions were realized to evaluate the test 
repeatability. Topography - and consequently roughness parameters - were determined, in addition to depth values associated with the layer removal. These procedures were carried out in an optical interferometer, Taylor Hobson Talysurf CCI Lite. The selected area for sampling was $0.825 \mathrm{~mm}$ x $0.825 \mathrm{~mm}$ for a resolution of 1024 x 1024 pixel. Figure 2 presents a schematic draw for the roughness measurements at the etched area. Roughness measurements were performed on the honed surface and in the polished area (central and edge). An evaluation of the height distribution of the roughness and the material ratio curve is presented. The following roughness parameters were used:

$>\mathrm{Sa}$ : Arithmetic mean height $[\mu \mathrm{m}]$;

$>$ Sq: Root mean square height $[\mu \mathrm{m}]$;

$>$ Spk: Reduced peak height $[\mu \mathrm{m}]$;

$>$ Sk: Core height $[\mu \mathrm{m}]$;

$>$ Svk: Reduced valley height $[\mu \mathrm{m}]$;

$>$ Sr1: Upper bearing area [\%]; and

$>\mathrm{Sr} 2$ : Lower bearing area [\%].

Table 1: Runs test parameters.

\begin{tabular}{l|l|l|l}
\hline \multirow{2}{*}{ TEST } & CONDITION & $\begin{array}{l}\text { ELECTRIC PO- } \\
\text { TENTIAL [V] }\end{array}$ & TIME [S] \\
\hline \multirow{5}{*}{$1^{\text {st }}$ run } & 1 & 20 & 30 \\
\cline { 2 - 4 } & 2 & 20 & 90 \\
\cline { 2 - 4 } & 3 & 30 & 60 \\
\cline { 2 - 4 } & 4 & 40 & 30 \\
\hline \multirow{5}{*}{$2^{\text {nd }}$ run } & 5 & 40 & 90 \\
\cline { 2 - 4 } & 1 & 20 & 45 \\
\cline { 2 - 4 } & 2 & 20 & 60 \\
\cline { 2 - 4 } & 3 & 30 & 45 \\
\cline { 2 - 4 } & 4 & 40 & 60 \\
\cline { 2 - 4 } & 5 & 40 &
\end{tabular}

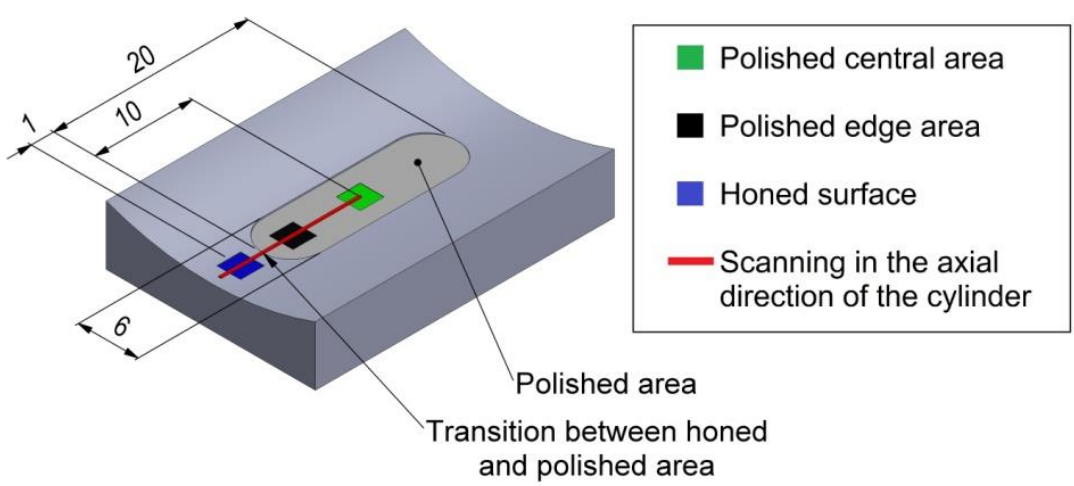

Figure 2: Schematic draw showing the roughness measurement at the etched area.

For the quantification of the layer removed with the polishing, depth evaluations were carried out in waviness profiles as presented in Figure 3. For this purpose, a scanning in the axial direction of the cylinder was performed, from the honed area until the polished central area, as shown in Figure 2. For measurements of depth and distance, a coordinate system was imposed, which is presented in Figure 3 . The height of the honed surface was considered as the reference for depth measurements, and the transition between the honed surface and the polished area was considered for distance measurement in the axial axis of the cylinder. Two results are presented and described below:

$>$ The mean depth of the layer removed along with the axial axis of the cylinder. The mean values 
(referred to the five repetitions) were presented in distance increments of $1 \mathrm{~mm}$;

The mean depth of the layer removed. This value considered the fifty evaluated points (10 per repetition).

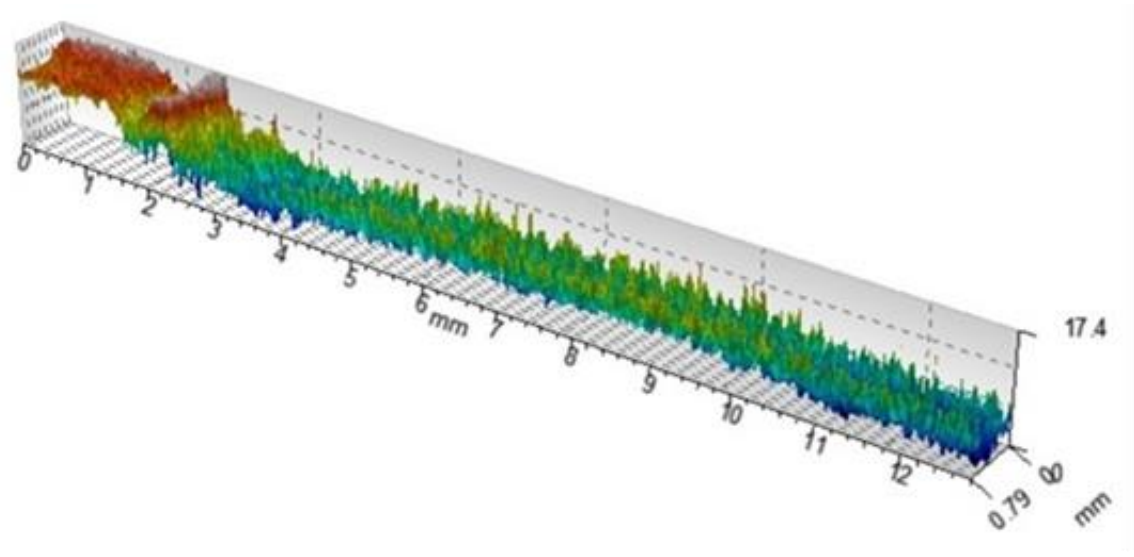

(a)

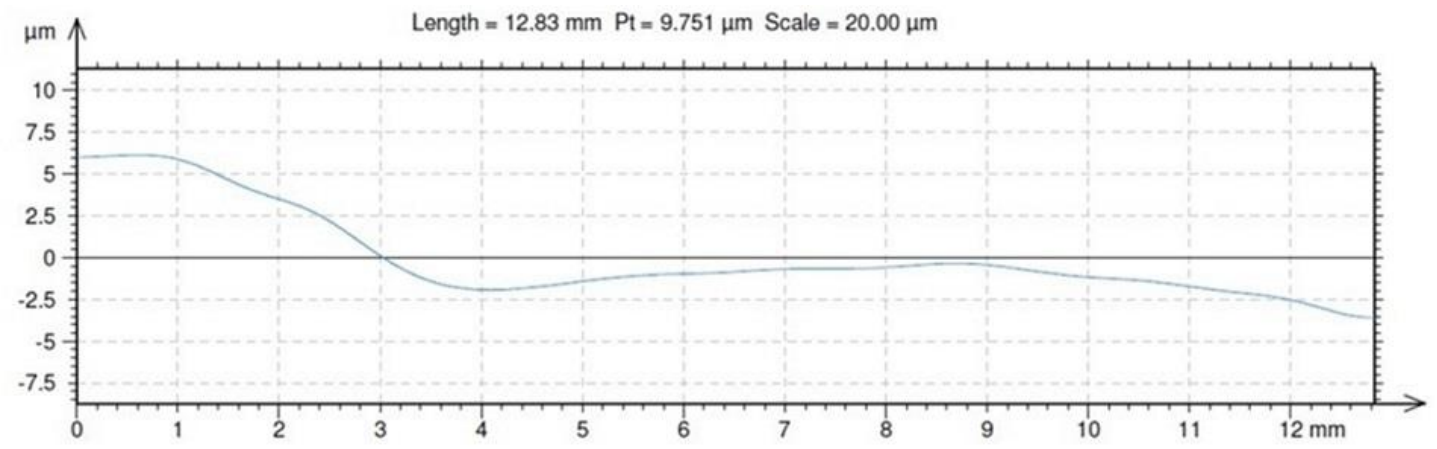

(b)

Figure 3: Characterization of the layer removal from the honed surface until the center of the region where occurred the electrolytic polishing. (a) 3D topography without filtering. (b) Filtered profile - Waviness.

\section{RESULTS AND DISCUSSION}

\subsection{Determination of ideal condition for electrolytic polishing}

Figure 4 presents a typical surface of a honed cylinder before the electrolyte polishing. A characteristic topography with plateaus and grooves, as seen elsewhere [2,3], can be observed in Figure 4.

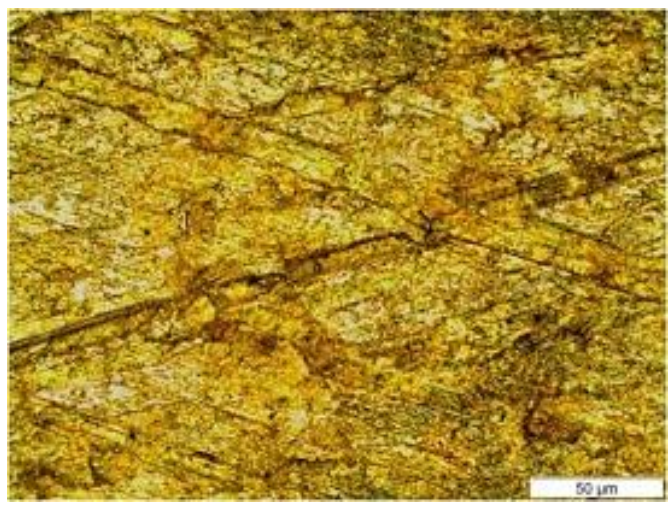

Figure 4: Superficial aspect of a typical honed surface before the electrolytic polishing. 
The result of the qualitative evaluation of etched surfaces is shown in Figure 5. Two runs of tests with five conditions of electric potential and time were required. The indications 1 and 2 presented in this chart refer to $1^{\text {st }}$ and $2^{\text {nd }}$ test runs, respectively.
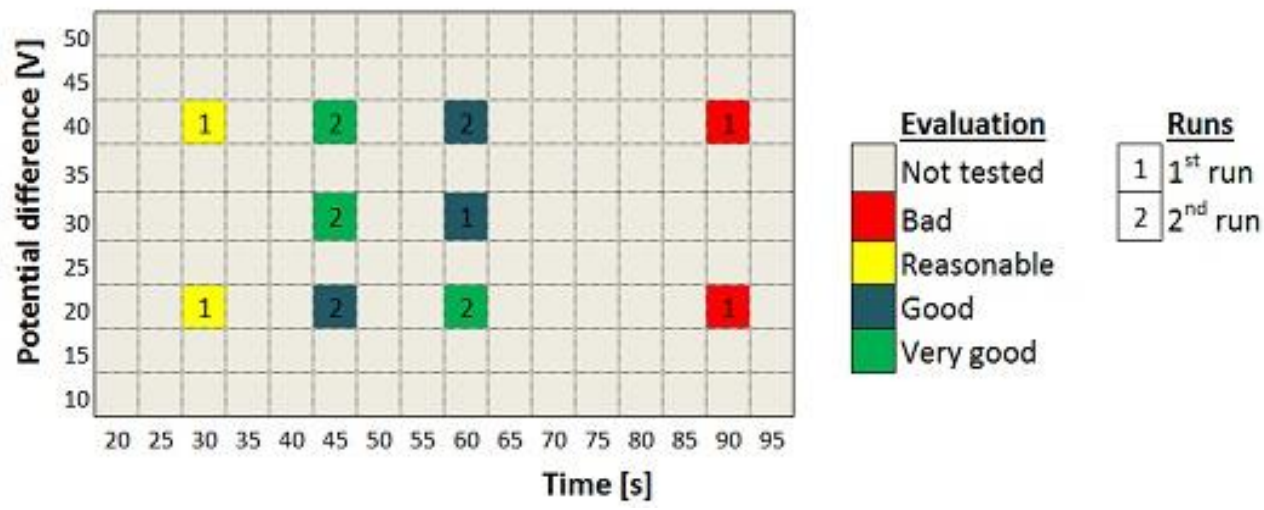

Figure 5: Qualitative chart for identifying the ideal polishing condition.

For the 1st run of tests, the conditions include the central point presented in Figure 5 as well as the border conditions in terms of time and electrical potential. Micrographs obtained for this run are presented in Figure 6. For a time of $90 \mathrm{~s}$, the surfaces are darker, resulting in worst aspects. On the other hand, the better aspect, characterized as 'good', was obtained for the central point condition. One can note that the metallic matrix revealing the pearlite. Furthermore, there was a significant change of surface roughness, eliminating the typical topography presented in Figure 4.

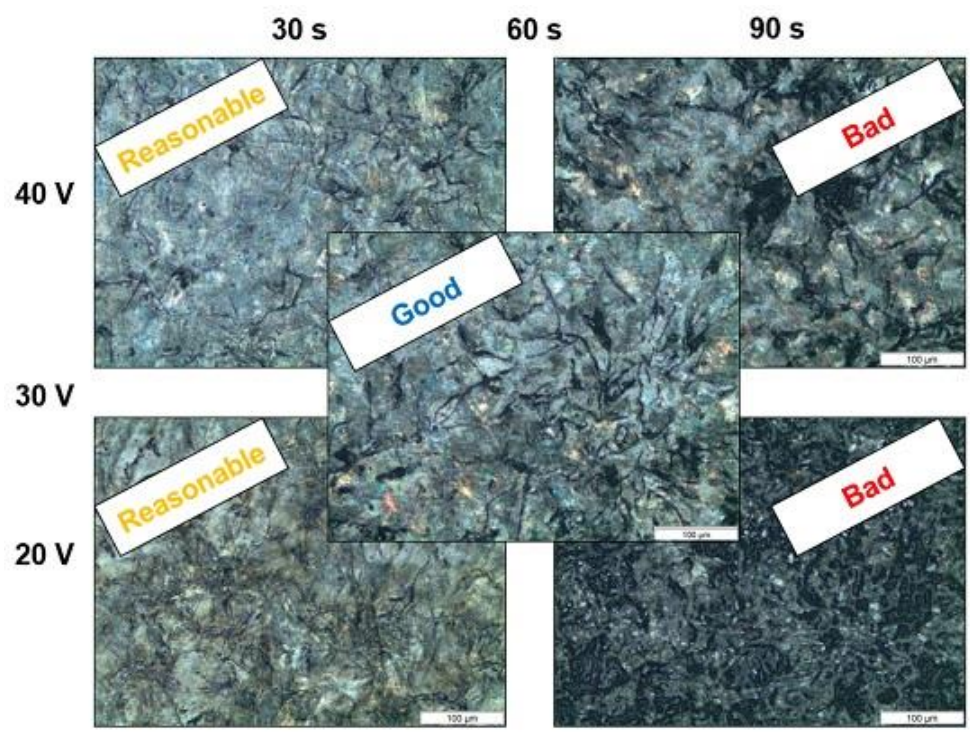

Figure 6: Optical micrographs and qualitative evaluation of 1st of tests of electrolytic polishing.

The results of the 2nd run are presented in Figure 7. Two conditions were evaluated as 'good' and three as 'very good'. Considering the contrast between graphite and matrix - an important characteristic for the procedure of segmentation through image analysis - the condition of $30 \mathrm{~V}$ and $45 \mathrm{~s}$ was chosen. 


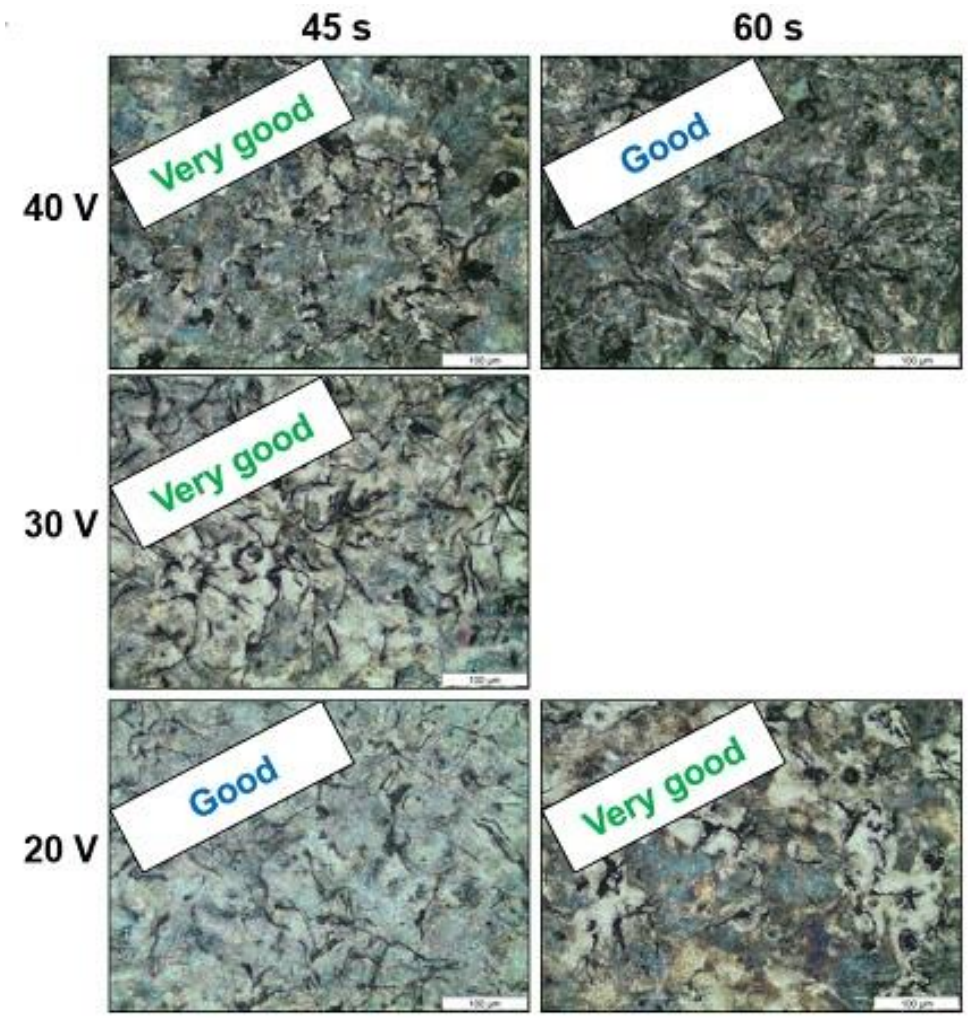

Figure 7: Optical micrographs and qualitative evaluation of 2nd run of tests of electrolytic polishing.

\subsection{Assessment of test repeatability}

The test repeatability was evaluated in 5 specimens using the ideal condition of $30 \mathrm{~V}$ and $45 \mathrm{~s}$. All tests resulted in polished surfaces with high-quality, graphite exposition and pearlite revelation. An example is presented in Figure 8.

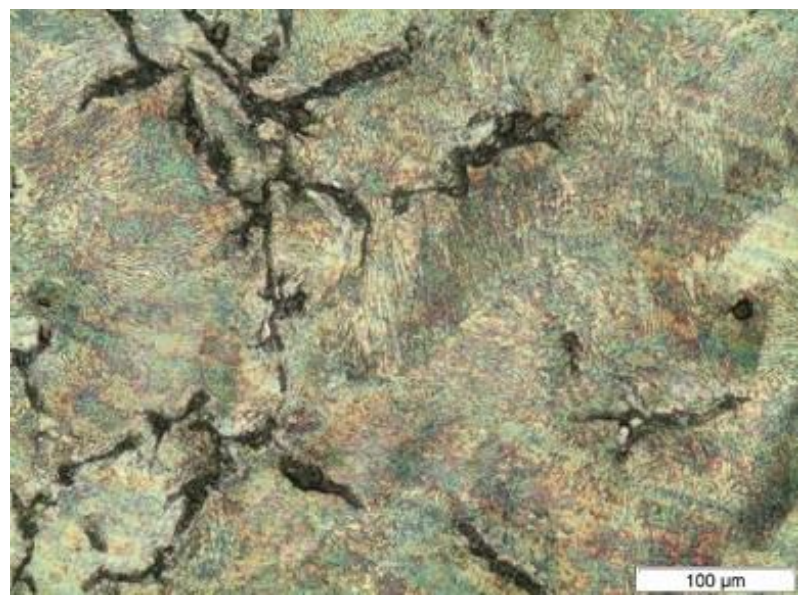

Figure 8: Optical micrographs for the best condition obtained after the electrolytic polishing [30 V - $45 \mathrm{~s}$ ].

Figure 9(a) and (b) show the 3D topography before and after the electrolytic polishing. After polishing, irregular portions (or 'islands') with sharp peaks can be noted, associated with deeper regions at the edges of these 'islands'. 

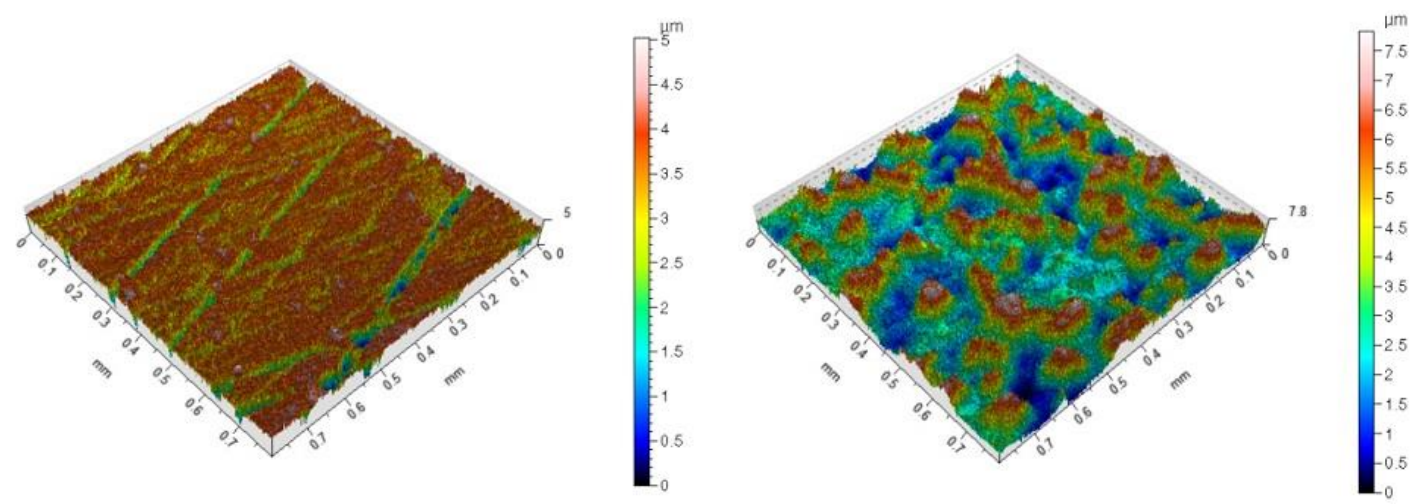

(a) (b)

Figure 9: Typical topography of surfaces: (a) before and (b) after electrolytic polishing.

Figure 10 shows the values for roughness parameters of the studied surfaces. One can note, in general, a significant change in the parameters with the electrolytic polishing. Comparing the results between the edge and central part of the polished region, an acceptable degree of homogeneity could be verified. Therefore, the following surface changes can be de-tailed:

$>$ An increase of amplitude parameters $\mathrm{Sa}$ and $\mathrm{Sq}$;

$>$ Changes associated with the peaks:

$\checkmark$ An increase of Spk;

$\checkmark$ A higher percentage associated to $\mathrm{Sr} 1$; in other words, an increase of regions associated to the peaks;

$>$ An increase of core (Sk), which follows the tendency of increase in the amplitude parameters;

$>$ The amplitude of valleys (Svk) became practically unaltered. Probably this behavior is due mostly to the formation of deeper contours around the 'islands' created by the polishing, as discussed in Figure 9. 


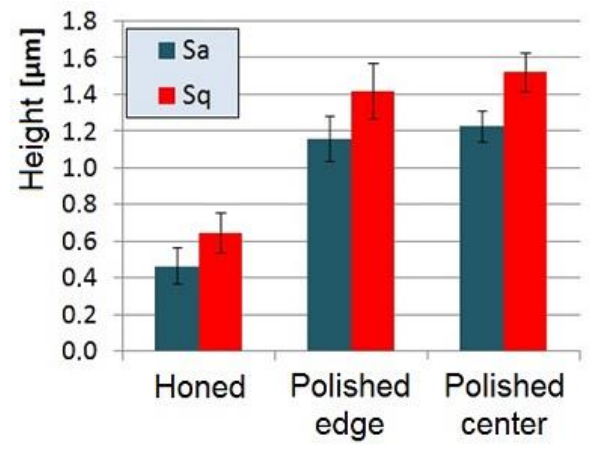

(a) Amplitude parameters

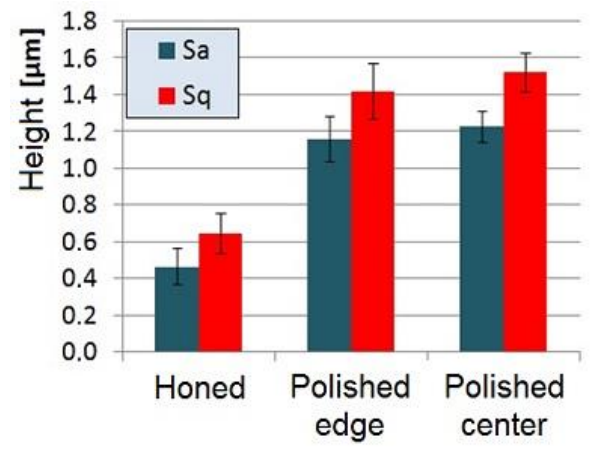

(b) Functional parameters-Familyk

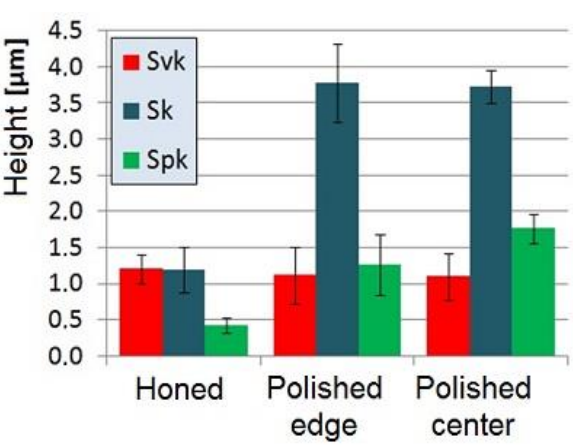

(c) Functional parameters - Sr1 e Sr2

Figure 10: Roughness parameters before and after electrolytic polishing

Figure 11 shows the drastic change, imposed by the polishing, on the height distribution of the roughness and the material ratio curve. An increase in the occurrence of greater depths is observed, even with the appearance of depths below $5 \mu \mathrm{m}$. Also, a displacement of heights distribution after polishing and a change of the material ratio curve can be noted, in which before the polishing there was a typical curve of honed surfaces.

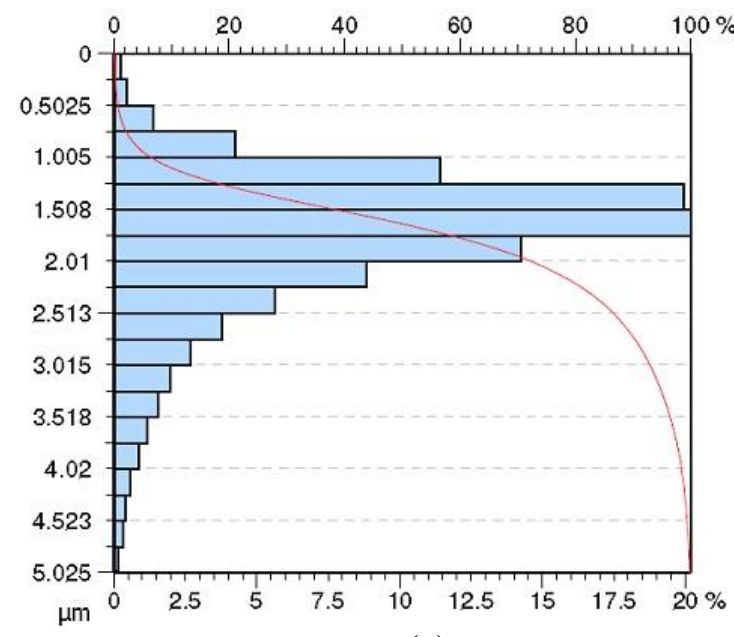

(a)

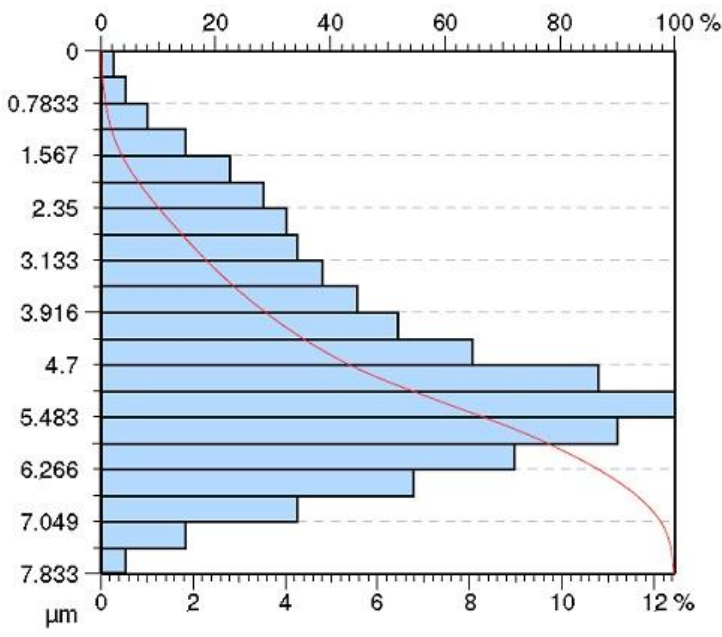

(b)

Figure 11: Typical heights distribution of roughness and material ratio curve: (a) before and (b) after electrolytic polishing. 
Obviously, the evaluation of Figure 9 and Figure 10 gives rise to a conclusion that the functionality of honed surfaces was completely lost. The general increase in roughness parameters did not compromise the evaluation of surfaces through optical microscopy.

The mean depth in relation to distance, related to the transition in the polished area, is presented in Figure 12. It was remarkable that this characterization refers to half of the polished region, as indicated in Figure 2. It is noted that the depth presents a high dispersion, but its mean values are very similar to the polished region, mainly beyond $2 \mathrm{~mm}$ of the transition of the polished region. The mean value of the depth removed was $-4.6 \pm 2.0 \mu \mathrm{m}$. Although the coefficient of variation is $42.5 \%$, the values obtained to meet the demand for this procedure to uncover the subsurface graphite, considering that this constituent has a characteristic dimension close to $10 \mu \mathrm{m}$.

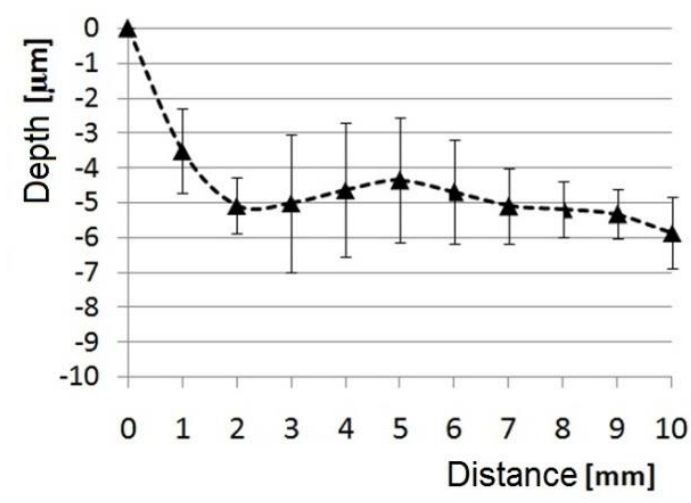

Figure 12: Depth of removed layer in relation to the relative distance of the electrolytic polishing.

\section{CONCLUSIONS}

The best condition of electrolytic polishing was determined for compacted cast iron, using a special mask and higher levels of solution flow. Based on the presented results, the following conclusions can be forwarded:

$>$ The ideal condition was identified through qualitative evaluation of micrographs, for the condition of $30 \mathrm{~V}$ for electric potential and $45 \mathrm{~s}$ for the time;

$>$ The repeatability of the tests for the ideal condition was considered satisfactory. There was a significant change in roughness parameters. However, it occurred in a considerably homogeneous manner along the polished area;

$>$ The depth of removed layer was in the order of micrometers and accomplishes the demand for the development of this technique for exposing the subsurface graphite.

\section{ACKNOWLEDGEMENTS}

The authors acknowledge Tupy S.A. for the supply of samples and the financial support through the Project ACT 10/2015 TUPY-UTFPR. G. Pintaude acknowledges CNPq by granting from Project 312385/2014-5.

\section{BIBLIOGRAPHY}

[1] SABEUR, M., IBRAHIM, D., MOHAMED, E. M., HASSAN, Z., "Energy efficiency optimization of engine by frictional reduction of functional surfaces of cylinder ring-pack system", Tribology International, v. 59, pp. 240-247, Mar. 2013.

[2] CORRAL, I. B., CALVET, J. V., "Roughness variability in the honing process of steel cylinders with CBN metal bonded tools", Precision Engineering, v. 35, pp. 289-293, Apr. 2011.

[3] MEZGHANI, S., DEMIRCI, I., ZAHOUANI, H., MANSORI, M. L., "The effect of groove texture patterns on piston-ring pack friction", Precision Engineering. v. 36, pp. 210-217, Apr. 2012. 
[4] OBARA, R. B., SOUZA, R. M., TOMANIK, E., "Quantification of folded metal in cylinder bores through surface relocation”, Wear, v. 384, pp. 142-150, Aug. 2017.

[5] DIMKOVSKI, Z., ANDERBERG, C., OHLSSON, R., et al., "Quantification of the cold worked material inside the deep honing grooves on cylinder liner surfaces and its effect on wear", Wear, v. 267, pp. 22352242, Dec. 2009.

[6] DO VALE, J. L., DA SILVA, C. H., PINTAÚDE, G., "Effect of graphite on folded metal occurrence in honed surfaces of grey and compacted cast irons", Surface Topography: Metrology and Properties, v.5, p. 035001 , Sept. 2017.

[7] RIVERA, G., BOERI, R., SIKORA, J., "Research advances in ductile iron solidification", AFS Transactions, v. 111, paper 3-159, pp. 979-989, 2003.

[8] SINATORA, A., ALBERTIN, E., \& MATSUBARA, Y., "An investigation of the transition from M7C3 to M3C carbides in white cast irons", International Journal of Cast Metals Research, v. 9, 9-15, Jul. 1996.

[9] DA SILVA, C. R. S., BOCCALINI, M., "Thermal cracking of multicomponent white cast iron", Materials Science and Technology, v. 21, pp. 565-573, May 2005.

[10] WOLLMANN, D., SOARES, G. P. P. P., GRABARSKI, M. I., et al., "Rolling Contact Fatigue Failure Mechanisms of Plasma-Nitrided Ductile Cast Iron", Journal of Materials Engineering and Performance, v. 26, pp. 2859-2868, May 2017.

\section{ORCID}

João Luiz do Vale Victor de Cerjat Beltrão Giuseppe Pintaúde https://orcid.org/0000-0003-4827-2278

https://orcid.org/0000-0002-6134-6254

https://orcid.org/0000-0001-8215-4481 